\title{
ESTRATÉGIAS CATAFÓRICAS EM NARRATIVAS AMAZÔNICAS: IMPLICAÇÕES PARA A CONSTRUÇÃO DA CADEIA TÓPICA E TEXTUAL
}

\author{
Heliud Luis Maia Moura* \\ Universidade Federal do Oeste do Pará \\ Instituto de Ciências da Educação \\ Programa de Letras \\ Santarém, PA, Brasil
}

\begin{abstract}
Resumo: Este artigo objetiva analisar estratégias catafóricas mobilizadas em narrativas afiliadas ao universo do lendário da Amazônia, observando, de acordo com as teorias acerca da referenciação, a forma como essas estratégias antecipam e projetam referentes a serem postos na cadeia textual. Toma, como referencial teórico, postulações de Tomasello (2003), Marcuschi (2007), Koch (1999, 2002, 2004) e Moura (2013). Consoante as postulações teóricas, considera a referenciação uma atividade discursiva, sociocognitiva e sociointerativa, pela qual reconstruímos, em linguagem, seres, objetos e eventos do universo biossocial. Assim, a realidade é construída pela maneira como agimos sociocognitivamente sobre esse universo (KOCH, 2004). O corpus em análise consta de 5 (cinco) excertos de narrativas de Boto, Cobra, Matintaperera e Curupira. A análise reafirma a premissa de que as estratégias catafóricas são tributárias de processos sociocognitivos e culturais em circulação no contexto em que as mencionadas narrativas circulam e são produzidas.
\end{abstract}

Palavras-chave: Linguística Textual. Referenciação. Narrativa amazônica. Estratégia catafórica.

\section{INTRODUÇÃO}

Este artigo constitui recorte de uma das categorias de análise realizadas em minha tese de doutorado ${ }^{1}$ e que tem por objetivo descrever estratégias catafóricas mobilizadas em narrativas afiliadas ao universo do lendário da Amazônia, compreendendo um corpus de 13 (treze) números da Revista Visagens, Assombrações e Encantamentos da Amazônia, de autoria do escritor paraense Walcyr Monteiro. Estes números foram produzidos entre os anos de 1997 e 2004 e versam sobre histórias de Boto, Cobra, Matintaperera e Curupira. Tais personagens são recorrentes tanto em narrativas orais quanto escritas, em circulação no contexto amazônico. Os mencionados números foram editados e publicados pela Editora Smith - Produções Gráficas, na cidade de Belém-PA. As histórias presentes nessa revista são (re)criações do mencionado autor, estando ancoradas no universo sociodiscursivo e cultural de sua produção.

\footnotetext{
* Doutor em Linguística pela Universidade Estadual de Campinas. E-mail: heliudlmm@ yahoo.com.br

${ }^{1}$ A tese foi apresentada em 2013 ao Instituto de Estudos da Linguagem, da Universidade Estadual de Campinas (UNICAMP) e teve como orientadora a Prof ${ }^{a}$. Dr ${ }^{a}$. Anna Christina Bentes da Silva.
} 
Considerando as 4 (quatro) entidades mencionadas, temos, portanto, 4 (quatro) temáticas gerais diferentes, concernentes a essas entidades, o que justifica a divisão em 4 (quatro) blocos distintos. Destaco também que os temas gerais, relativos aos 4 (quatro) personagens em pauta, não são homogêneos ou uniformes, já que contêm significados ou subtemas específicos dentro de cada um deles, os quais se referem às características ou particularidades das narrativas que aí estão inseridas.

As estratégias catafóricas em análise constituem recursos pelos quais o produtor textual dá andamento ao processo narrativo. Assim, à medida que o percurso tópicotemático avança, novas predicações são realizadas sobre um dado referente, implicando também aí recategorizações, de modo que, a partir desse processo, o referente principal possa ser ativado e posto na cadeia textual. No caso dos excertos analisados, as estratégias catafóricas se apresentam como constitutivas das narrativas em apreciação, com a inserção de novos eventos e situações, essenciais para a construção do relato em mobilização na história que está sendo produzida.

Vale ressaltar que os processos catafóricos estão ligados as formas de gerenciamento do tópico discursivo como a antecipação de elementos referenciais construtores de seres e eventos a serem postos subsequentemente na cadeia tópica, consoante o projeto de dizer do produtor textual, ao mesmo tempo que projetando determinados referentes, essenciais ou subsidiários a esse projeto de dizer, levando-se em consideração, nesses processos, fatores sociocognitivos e culturais, como é o caso das narrativas aqui analisadas.

\section{BASES TEÓRICAS}

A referenciação tem ocupado um lugar privilegiado no campo dos estudos da linguagem, mais especificamente no âmbito dos estudos da cognição, aqui, por sua vez, tomada como um conjunto de fundamentos epistemológicos alicerçados na ideia de que as construções simbólicas, incluindo-se, aí, a linguagem verbal, são produto de interações e formações social e culturalmente situadas, tributárias de processos históricos. Por essa acepção, é válido postular que as atividades referenciais, mediadas pela linguagem, envolvem processos sociocognitivos baseados em estruturas de conhecimento atreladas às experiências sociointerativas dos sujeitos, resultantes dos próprios contextos em que tais sujeitos transitam e estão inseridos.

Mas, como já afirmado, pensar a referenciação enquanto atividade linguísticodiscursiva é levar em conta os fatores cognitivos implicados na construção das atividades referenciais, que se instituem como sociointerativos ${ }^{2}$, pragmáticos e encarnados nas práticas culturais mais amplas e estritas, por meio dos quais as atividades linguísticas adquirem significação.

Com base nesse pressuposto, vejamos o que diz Tomasello:

\footnotetext{
${ }^{2}$ Quando falo de fatores sociointerativos, refiro-me às interações, por meio das quais, os sujeitos carreiam sentidos já construídos relativos aos elementos referenciais em estudo. 
O domínio por parte das crianças de um artefato cultural muito especial - a linguagem - opera efeitos transformadores sobre sua cognição. A linguagem não cria novos processos cognitivos do nada, é claro, mas, quando as crianças interagem com outras pessoas intersubjetivamente e adotam suas convenções comunicativas, esse processo social cria uma nova forma de representação cognitiva - uma forma que não encontra contrapartida em outra espécie animal. A novidade é que os símbolos linguísticos são ao mesmo tempo intersubjetivos e perspectivos. A natureza intersubjetiva dos símbolos linguísticos humanos implica que eles são socialmente "compartilhados" de uma maneira que os sinais animais não são, e isso forma a matriz pragmática na qual muitas inferências sobre as intenções comunicativas dos outros podem ser feitas - por que eles escolhem um símbolo e não outro que eles também compartilham com o ouvinte, por exemplo. A natureza perspectiva dos símbolos linguísticos implica que, quando as crianças aprendem a usar palavras e construções linguísticas da maneira dos adultos, acabam percebendo que exatamente o mesmo fenômeno pode ser interpretado de muitos modos diferentes para diferentes propósitos comunicativos, dependendo de muitos fatores no contexto comunicativo. (TOMASELLO, 2003, p. 298)

Acrescente-se, de acordo com o autor em citação, que as representações linguísticas construídas nas diferentes interações não estão presas ao contexto perceptual imediato, não apenas no sentido de que, com essas representações simbólicas, as crianças podem se reportar a coisas e falar delas, mesmo que estas estejam afastadas destas no tempo e no espaço, mas também no sentido de que a mesma entidade, visivelmente e perceptivamente presente, pode ser representada linguisticamente de inúmeras e diferentes maneiras. Ainda para o autor em questão, talvez isso seja paradoxal se consideramos a era dos computadores e das interações virtuais, levando em conta que essas formas radicalmente novas e poderosas de representação cognitiva não dependem de novos recursos de armazenamento ou de faculdades de computação dentro do cérebro humano; dependem, sim, de novas formas de interação social, construídas por novas formas de cognição social, que passam a ocorrer entre indivíduos nas mais diversas culturas humanas.

Diante das postulações de Tomasello (2003), é importante também acrescentar que a natureza referencial da linguagem reside na dinâmica do gerenciamento dos sentidos requeridos pelos diversos contextos, que se apresentam quase sempre complexos e internamente multifacetados, heterogêneos e contraditórios, com ativação, reativação e desativação desses sentidos, levando-se em conta, nesse âmbito, o fato de que as interações são emergenciadas e contingenciadas pelo caráter das situações sociocomunicativas em que estão imersas, mas que também podem escapar a esse caráter, em razão da própria dinâmica que lhes é tributada.

Nos dizeres de Marcuschi (2007), a referenciação constitui uma instância sociodiscursiva e sociointerativa por meio da qual construímos o mundo de nossas vivências. Assim, o ato de referenciar demanda um conglomerado de processos e fatores sociocognitivos, nos quais as diversas experiências adquiridas e elaboradas socialmente são reconstruídas e transmitidas via ações e interações de diferentes naturezas. Logo, ampliando um pouco o que aqui foi parafraseado, o autor afirma ainda que:

[...] a construção referencial deve ser tida como central na aquisição da língua, estendendose a todas as ações linguísticas. Considerando que a língua em si mesma não providencia a determinação semântica para as palavras e as palavras isoladas também não nos dão sua dimensão semântica, somente uma rede lexical situada num sistema sócio-interativo permite a produção de sentidos. Assim, dizer que todo sentido é situado equivale a postular que nada se dá isoladamente. (MARCUSCHI, 2007, p. 69-70). 
Tendo em vista o posicionamento do autor, proponho que a referenciação, enquanto atividade sociodiscursiva e sociointerativa, pode ser caracterizada como encampando os seguintes aspectos:

a) multiplicidade e heterogeneidade de processos e/ou procedimentos;

b) não exaustividade quanto ao número desses processos e/ou procedimentos;

c) distribuição irregular de formas referenciais na língua;

d) possibilidade de uma reclassificação das formas supracitadas;

e) criação de novas teorizações, considerando novos fenômenos referenciais encontrados na língua;

f) reanálise ou reinterpretação teórica de fenômenos referenciais já descritos na língua;

g) construção de novos paradigmas teóricos gerais acerca do fenômeno;

h) observação do fato de que se constitui um fenômeno amplo e eclético, envolvendo estratégias textual-discursivas variadas, conectadas com a ação sociocomunicativa e sociointerativa do produtor de um determinado texto ${ }^{3}$.

Portanto, considerando os 8 (oito) itens propostos, postulo que a referenciação não é um fenômeno estanque e isomórfico, mas uma atividade textual-cognitivo-discursiva que engloba uma variedade de processos e estratégias relativas à produção do sentido, os quais, por sua vez, estão embutidos nas práticas interacionais que permeiam as ações humanas em seus diferentes níveis e instâncias. Logo, são as estruturas de sentido que conduzem ou mobilizam as formas referenciais no concurso da atividade textual, que, sendo múltipla, heterogênea e emergenciada em seus vários contextos, produz uma infinidade de recursos ou estratégias de referência, ancorados tanto na materialidade do texto como em elementos exofóricos participantes do ato enunciativo.

Acrescentando ao que foi dito no parágrafo anterior, proponho, ainda, ser possível que os tipos de atividades referenciais sejam resultado de determinadas operações linguísticas implementadas pelo produtor de um dado texto e do modo como essas operações se concretizam em termos não só puramente textuais, mas também em nível semântico e discursivo, compreendendo-se, nesse âmbito, vários recursos dos quais se vale esse produtor para compor certos textos, como os que interagem as narrativas que são objeto de investigação neste artigo. Narrativas estas que se caracterizam por conter elementos relacionados ao lendário e cuja estrutura de referência reatualiza os sentidos expressos por esses elementos. No entanto, o que se postula propriamente aqui é o fato de as atividades de referenciação se constituírem como diversificadas ou diferenciadas nas práticas textuais, com uso de recursos referenciais específicos para determinados textos, tendo-se também em conta, aí, não só a sua multiplicidade, mas, sobretudo, o caráter heterogêneo que lhes é inerente, o que implica também, nesse contextos, a descrição de um conjunto de processos e/ou estratégias caracterizáveis como integrantes

\footnotetext{
${ }^{3}$ É no âmbito da natureza dessa ação sociocomunicativa e sociointerativa que os processos referenciais tomam forma, de modo a coadunarem-se com o "conjunto" de sentidos pretendidos pelo produtor textual. Ao falar em ação sociocomunicativa, refiro-me às diferentes maneiras pelas quais o(s) produtor(es) textual(ais) acionam os objetivos comunicativos no âmbito da construção das narrativas concernentes aos personagens afiliados ao lendário em estudo, o que concede um estatuto sui generis a essas ações comunicativas, no contexto em que circulam e fazem sentido.
} 
da própria natureza de algumas atividades textuais. Essa natureza, por seu turno, está atrelada à realidade social e cultural, compreendendo-se, nesse entorno, que as práticas textuais são construídas e mobilizadas a partir de sua inserção num dado universo sociocultural, ímpar, específico e característico, mas também atravessadas por elementos de outros universos, de outros contextos ou de outras construções simbólicas, o que vai resultar, obviamente, numa espécie de perfil relativo à construção dos textos em circulação numa sociedade, com a presença, nestes, de processos referenciais associados ao próprio caráter de tais produções.

Frente ao exposto, considerando o modo como os processos referenciais atuam na reconstrução da realidade biossocial e cultural, vejamos como Koch (2004) se posiciona em relação ao fenômeno da referenciação:

\begin{abstract}
Defendemos a tese de que o discurso constrói aquilo a que faz remissão, ao mesmo tempo que é tributário dessa construção. Como dissemos, todo discurso constrói uma representação que opera como uma memória compartilhada (memória discursiva, modelo textual), "publicamente" alimentada pelo próprio discurso (Apothéloz \& Reichler-Béguelin, 1995), sendo os sucessivos estágios dessa representação responsáveis, ao menos em parte, pelas seleções feitas pelos interlocutores, particularmente em se tratando de expressões referenciais. (KOCH, 2004, p. 61)
\end{abstract}

Conforme expresso pela citação da autora, posso afirmar que a referenciação constitui um conjunto de estratégias por meio das quais o sujeito dá sentido ao mundo biossocial, não só reconstruindo-o por meio de suas interações, mas imprimindo novas significações o que já está significado, desconstruindo, refutando, anulando ou acrescentando sentidos que se façam necessários a essas interações, permeadas sempre pela contradição, pelos paradoxos e mesmo pelos desacordos, inerentes às vivências humanas em suas várias dimensões e estágios.

Segundo Koch (1999, 2002), o sujeito opera escolhas significativas para representar situações, circunstâncias e estado de coisas, com a intenção de concretizar sua proposta de sentido, de modo que a interação verbal possa se realizar a contento. No entanto, indo um pouco além das postulações de Koch, proponho que as escolhas realizadas pelos sujeitos não são propriamente deliberadas, claras e totalmente premeditadas. Nesse sentido, os processos referenciais, devido à opacidade da língua, são complexos e, muitas vezes, não deliberados, o que implica dizer que envolvem construções referenciais dinâmicas, também complexas e nem sempre advindas de uma reflexividade semânticodiscursiva transparente, no âmbito das diferentes interações e dos contextos nas quais estas se realizam.

\title{
3 ANÁLISE DAS ESTRATÉGIAS CATAFÓRICAS
}

A observação de estratégias de progressão referencial ligadas à construção de referentes nas narrativas em análise levou-me a detectar a presença de cadeias referenciais catafóricas, cuja função básica consiste em introduzir referentes temáticos centrais, os quais estão diretamente atrelados ao tópico que está sendo carreado/pretendido pelo produtor do texto. 
Por outro lado, a cadeia catafórica se constitui de uma sequência de elementos que irão "desaguar" num referente principal, que se apresenta como nodal para todo o processo narrativo. À medida que tal cadeia avança, novas predicações são feitas acerca de um dado referente, o que pode implicar também recategorizações acerca desse mesmo elemento, até que possa ser introduzido o referente principal e inusitado, que se pode considerar como não previsto e capaz de provocar uma espécie de quebra no processo de referenciação em "andamento" no texto.

A mencionada cadeia catafórica pode se realizar no texto como um todo ou em porções textuais mais longas, de modo a assegurar a continuidade do tópico e, ao mesmo tempo, prender o interesse do leitor, tendo em vista o que vai ser desvelado mais adiante no texto. Do ponto de vista textual-discursivo, constitui um recurso importante para requalificações de um referente e para a inserção de novas informações acerca deste, de seu modo de agir do ponto de vista do narrador, inserindo-se também, aí, novos eventos ou situações que se instituem como cruciais para a construção do enredo da história que está sendo contada.

Assim, no caso das narrativas em estudo, as catáforas ajudam nas formas de construção dos personagens em pauta, afiliadas ao universo lendário, pois englobam estratégias de enredo que favorecem a implementação de recursos essenciais à compreensão de crenças voltadas para esses entes e para alguns modos por meio dos quais são culturalmente construídos e socialmente significados em produções escritas, como as aqui analisadas.

Acrescente-se que, neste trabalho, as catáforas são analisadas tanto em nível micro quanto em macrotextual. No primeiro, porque considero sua composição mais estrita em termos da estrutura das cadeias referenciais, conforme postulado por Koch. Para isso, conferir Koch (2006, p. 85), a saber:

a) uso de pronomes ou elipses (pronome nulo);

b) uso de expressões nominais definidas;

c) uso de expressões nominais indefinidas.

Já no segundo nível (macrotextual), porque levo em conta o processo de progressão contínua do texto ou de porções deste para a inserção ou introdução de um referente temático principal, o que vem ser operacionalizado por meio de uma cadeia referencial.

Vale ressaltar que, considerando a progressão textual em nível de um contínuo, foco mais propriamente no âmbito macrotextual, visto que as cadeias catafóricas operam, no caso aqui analisado, na perspectiva projetiva, de modo a antecipar referentes a serem enunciados dentro do texto como um todo ou em parcelas mais amplas.

Vejam-se os trechos 1 e 2 em exemplo:

1.

Rio Laguna, afluente do rio Tajapuru, Município de Melgaço. Há alguns anos, mais ou menos na década de sessenta, um senhor estava muito preocupado. Ele era pai de dois rapazes, Jorge e Júnior, e os dois eram o motivo de sua preocupação.

Quem vai contar a história é Tereza Carvalho Rodrigues, estudante e natural do Município de Melgaço. 
Os filhos haviam arranjado uma amiga - ou seria namorada? - há algum tempo e daquele momento em diante não queriam saber de nada, nem mesmo de comer. O pior era que o pai de Jorge e Júnior não sabia quem era a mulher. Não a conhecia do Rio Laguna e adjacências. Ela só vinha à noite, o que lhe aumentava a preocupação.

O mais estranho era que os dois aceitavam aquela situação com a maior naturalidade, ou seja, era como se os dois namorassem com ela e ela satisfizesse os dois...

O pai, mais do que desconfiado, começou a espionar. E viu que a mulher, quando chegava à noite, levava comida para eles, que a comiam avidamente. Aí descobriu por que não queriam mais comer a comida que a mãe preparava... Também verificou que Jorge e Júnior ficavam muito tempo tomando banho no rio, como se de lá não quisessem sair... e também estranhou a irresistível atração pela água!

Chamou os filhos para uma conversa séria, dizendo que aquela mulher não deveria ser uma mulher comum, uma mulher qualquer, que ali tinha coisa, que aquela mulher os estava encantando e que não deveriam mais comer da comida que ela levava, pois eles iam cada vez mais ficar interessados por ela e que ela ia acabar levando-os, sabe Deus para onde!

Mas Jorge e Júnior não deram atenção às palavras do pai, que aumentou a vigilância, pois sabia que, se os deixasse sozinhos à noite com ela, ela os levaria...

Então, quando dava uma certa hora, ele chamava os filhos e segurava-os, não os largando de jeito nenhum. A mulher ia embora muito aborrecida, mas continuava indo toda noite, só esperando uma oportunidade de ficar só com os dois..

A vida havia se tomado um inferno para o pai, que se via obrigado àquela vigília forçada todas as noites e todas as horas, pois, durante o dia, era a vontade de se banharem no rio...

Até que resolveu por termo àquela situação e livrar os filhos de uma vez por todas. E falou consigo mesmo:

- E, eu vou matar esta Bôta, antes que ela leve meus filhos.

Já não tinha dúvidas: com certeza que se tratava mesmo de uma Bôta. [...] (MONTEIRO, 2000b, p. 15-17).

2.

[...] Cismou que ela ia levá-los no dia seguinte. E antes que ela se dirigisse para a casa deles, foi esperá-la perto do trapiche.

Realmente ela veio. Ele estava escondido atrás de uma touceira de açaizeiros. Quando ela se aproximou, ele saiu e, com um revólver, atirou à queima-roupa em cima do peito da mulher, que caiu morta na praia.

Jorge e Júnior, ao darem falta do pai em casa, tinham saído atrás dele. E viram tudo. Quando a mulher caiu, os dois foram pra cima dela, chorando muito, abraçando e beijando o cadáver. Aí o pai falou:

- Meus filhos, não chorem por causa desta mulher que ela não é gente igual a nós. Ela é uma Bôta... [...] (MONTEIRO, 2000b, p. 17).

Como podemos observar no excerto 1, o referente principal, esta Bôta, introduzido já no final da sequência narrativa, vem antecipado por uma cadeia catafórica constituída por diversos elementos, cuja função consiste em apontar para o que se institui como o foco central do processo narrativo: o personagem que deve ser desvelado, tendo em conta os propósitos do produtor do texto.

$\mathrm{Na}$ cadeia referencial posta em "andamento", diversos referentes são introduzidos e os objetos-de-discurso assumem categorias diferentes, no entanto, têm a função precípua de construir o que se constitui como essencial para o enredo de uma forma típica de narrativa: aquela em que a entidade o Boto ou Bôta se antropomorfiza em diversos tipos de personagens humanos.

MOURA, Heliud Luis Maia. Estratégias catafóricas em narrativas amazônicas: implicações para a construção da cadeia tópica e textual. Linguagem em (Dis)curso - LemD, Tubarão, SC, v. 18, n. 2, p. 273-286, maio/ago. 
Assim, neste primeiro exemplo, a cadeia referencial catafórica é implementada por meio das seguintes expressões nominais indefinidas e definidas: uma amiga, namorada, a mulher, aquela mulher, uma mulher comum, uma mulher qualquer, que realizam, neste caso, três distintos referentes e categorias: amiga, namorada, mulher. Logo, no contínuo da progressão textual, a categorização muda, mas essa mudança se presta à introdução de um novo referente, cuja função é quebrar a expectativa do leitor. É válido acrescentar também que os diferentes referentes textuais em questão vão construindo uma imagem específica do objeto-de-discurso a Bôta, o qual vai ser introduzido logo depois na cadeia tópica ou referencial.

Embora possamos detectar a presença de anáforas no decorrer da progressão temática, como no caso em que a expressão nominal definida a mulher remete às formas indefinidas namorada e uma amiga, tal estratégia, no conjunto da atividade referencial, constitui um recurso por meio do qual a progressão temática avança, indo descambar no efeito vislumbrado pelo narrador: definir, em nível temático maior, o objeto pretendido pela ação verbal que foi colocada em curso.

Ainda no mesmo excerto, temos a presença de estratégias de progressão como o uso de pronomes e elipses (pronome nulo), que também são utilizados no processo de delineamento do referente temático central.

Assim, no que concerne a este excerto, observamos como a estratégia catafórica ou antecipadora do objeto-de-discurso a ser desvelado mais adiante continua a ser mobilizada pelo produtor/narrador no processo de construção da atividade narrativa:

Então, quando dava uma certa hora, ele chamava os filhos e segurava-os, não os largando de jeito nenhum. A mulher ia embora muito aborrecida, mas continuava indo toda noite, só esperando uma oportunidade de ficar só com os dois... (MONTEIRO, 2000b, p. 17).

Como podemos detectar no trecho em exemplificação, os constituintes a mulher (expressão referencial) e continuava indo e esperando (predicação) constituem elementos que também têm a propriedade de construir, no decurso da progressão temática, o objeto de discurso a ser posto na cadeia referencial, no caso, esta Bôta. Logo, a expressão referencial a mulher, encapsulando agora informações tais como continuava indo e esperando uma oportunidade de ficar só com os dois possui um caráter catafórico de qualificar/construir as informações acerca do referente, de modo a se constituir como um recurso preparador e prévio do referente temático ou principal, que, nesta altura do processo narrativo, ainda não foi introduzido no texto.

$\mathrm{O}$ exemplo 2, ainda pertencente à narrativa anterior, apresenta um conjunto de expressões verbais que, vindo encabeçadas pelo pronome ela, têm a função de conduzir progressivamente a atividade tópica. No entanto, postulo aqui que o papel dessas expressões, no que diz respeito ao processo de introdução do referente principal, é o de servir concomitantemente de ponte no movimento duplo de retroação e projeção referencial, ou seja, ao mesmo tempo que remetem às expressões nominais que apontam para o referente temático principal, também introduzem informações novas, necessárias à delineação e construção dos eventos constituintes da elaboração do enredo, os quais, 
obviamente, estão atrelados a esse personagem nuclear. Desse modo, enunciados como ela ia levá-los; antes que ela se dirigisse; ela veio; ela se aproximou, os quais, sendo introduzidos por um pronome, constituem instrumentos referenciais de condução da ação narradora e que, também servindo como âncora para a predicação acerca do referente temático ou principal, têm o papel de antecipá-lo e/ou anunciá-lo no curso desta mesma ação. Nesse caso, tanto retomam referentes já postos na cadeia textual, quanto proporcionam a inserção de novas informações ou fatos. Acrescento ainda que, em se tratando de sua função antecipadora, tais elementos auxiliam na elaboração de predicações que concorrem para a construção do personagem central: a Bôta.

Veja-se o trecho 3 em exemplo:

3.

“- Foi mais ou menos em 1965. Meu pai era agricultor, plantava malva, juta, melancia, jerimum, mandioca, macaxera, estas coisas. Além disto, ele gostava de caçar e de pescar nas horas em que não estava envolvido com a agricultura. Caçava muitas vezes de noite, passando horas e horas, e uma vez foi até atacado por uma onça. Também nas pescarias ouvia muitas histórias de Cobra Grande, mas não dava bola... Era muito corajoso!

Mas... aconteceu numa noite e toda a coragem de meu pai foi colocada à prova. Era o ano de 1965, época da cheia, setembro/outubro. Ele saiu para uma pescaria no Rio Amazonas, lá defronte de Barreira do Tapará. No que estava pescando, viu aquela coisa enorme, monstruosa, se mexendo no rio. Era a Cobra Grande, com seus enormes olhos como se fossem tochas de fogo." [...] (MONTEIRO, 2002, p. 15-16).

Quanto ao exemplo 3, retirado de uma narrativa de Cobra Grande, temos a presença de duas expressões catafóricas: aquela coisa enorme e monstruosa, constituindo processos relativos à predicação do referente a ser posto na cadeia textual. Estas, junto com a expressão verbal se mexendo no rio constituem procedimentos catafóricos. Assim, na cadeia referencial, a forma nominal aquela coisa enorme vem recategorizada pela expressão monstruosa. Entre essas expressões (aquela coisa enorme e monstruosa) há uma espécie de gradação. A inserção da construção se mexendo no rio, vai, finalmente, definindo melhor o objeto de discurso a Cobra Grande, primordial dentro da história que está sendo contada.

Veja-se o trecho 4 em exemplo:

4.

[...] Quando chegaram no local, sobre um galho de uma árvore próxima às duas cuias pitinga em cima da sandália emborcada, estava uma mulher que dali não conseguia se mexer, como se estivesse amarrada no galho. O pajé disse para João Piraqueira:

- Esta é a Matinta Perera que estava perturbando vocês...!

Quando João Piraqueira ergueu a vista para o galho da árvore, quase desmaiou. Quem estava lá em cima era a sua própria mãe, a Tia Podó... [...] (MONTEIRO, 2007, p. 18).

Já no exemplo 4, relativo a uma narrativa de Matintaperera, temos uma sequência catafórica que inicia pela forma nominal uma mulher, passa por várias catáforas (não conseguia se mexer, como se estivesse amarrada no galho; a Matinta Perera; a sua própria mãe) e chega até a expressão a Tia Podó, a qual constitui o referente final a ser desvelado no processo narrativo. 
Logo, no percurso catafórico, observo a presença de vários referentes que aí são introduzidos e que contribuem para a sequenciação dos eventos colocados em curso no texto. Esses referentes pertencem a várias categorias: mulher, Matintaperera, mãe e tia, que, de forma direta ou indireta, estão associados ao personagem central veiculado pela atividade tópica, que é a própria Matintaperera. No cotexto, esse personagem tem a característica de se manifestar de diferentes maneiras, evidenciando também que, no contexto cultural ao qual está atrelado o texto, assume diversas categorizações, com significados ligados às práticas sociais aí existentes.

Veja-se o trecho 5 em exemplo:

5.

[...] Numa tarde, estávamos todos nós para um lado do roçado, e Ulisses, sozinho, estava trabalhando noutro local, um pouco distante. Eram cerca de seis horas da tarde quando ouvimos gritos de socorro. A voz não enganava: era de Ulisses. Corremos na direção dos gritos e ali encontramos Ulisses apavorado, sem conseguir sair de onde se encontrava. Mal conseguia falar. Quando pôde dizer alguma coisa, contou que estava trabalhando, quando sentiu como que uma presença perto de si. Ao olhar em torno, deu com aquele caboclinho bem perto. Espantou-se. Mais ainda porque não ouvira nenhum sinal de sua aproximação. Entretanto o caboclinho estava ali, a olhá-lo atentamente. Todo nu, o corpo moreno parecia feito de lascas de madeira marrom, como se fosse uma proteção...

Neste momento, Ulisses quis se mexer e não conseguiu. Sentiu-se estontear e pareceu ter perdido a noção do lugar, como se não soubesse onde estava... Foi quando começou a gritar. Ele não viu que direção tomou o caboclinho, só que quando chegamos não encontramos ninguém ali... Às 6 horas da tarde, no mato, fica tudo escuro como se fosse noite. Mas Ulisses afirmou que havia se encontrado com o Curupira. [...] (MONTEIRO, 2000a, p. 21).

Por fim, no exemplo 5, observo uma cadeia catafórica relacionada ao Curupira, expressa por meio de nove expressões nominais, as quais apontam para esse referente temático central. Nessa cadeia referencial mais longa, a construção da atividade referenciadora ocorre por meio de estruturas nominais diversificadas, algumas mais breves e simples, outras mais extensas e complexas, contendo valores semânticos também diferenciados no que concerne à construção de referência. Assim, a expressão nominal indefinida uma presença tem sua definição na expressão aquele caboclinho que, por sua vez, é retomada pela forma nominal complexa nenhum sinal de sua aproximação, a qual passa a ser, logo depois, referenciada pela forma o caboclinho, reconstruída posteriormente pelas expressões nominais todo пи e o corpo moreno. Finalmente, o referente central "Curupira" é introduzido.

Como se vê, a cadeia catafórica constitui-se de um contínuo referencial-progressivo longo, cuja função é propiciar a colocação de um elemento não previsto, mas que já é, de diversas maneiras, antecipado por catáforas que o indiciam na estrutura referencial.

Com base no exposto, postulo que as estratégias catafóricas têm, no caso das narrativas em estudo, a propriedade de manifestar diferentes tipos de referentes e categorias que concorrem para a inserção de um personagem nodal ou temático principal dentro do texto, o qual, por seu turno, se coaduna com os objetivos perpetrados por uma determinada ação verbal. 
Nas narrativas em análise, as catáforas em sequência atuam no sentido de préfigurar ou pré-construir ${ }^{4}$ o referente temático em jogo na atividade discursiva, não tal e qual se constitui em termos de referente, ou seja, na sua recursividade sociocognitiva e cultural, mas enquanto elementos que o indiciam, realizando-se estes por meio de diversos outros referentes, categorias e formas textuais.

Portanto, os processos catafóricos em questão são tributários de estratégias discursivas que operam na perspectiva de desfocalização de um referente pretendido previamente dentro da atividade enunciativa, realizando-se nos mais variados objetos-dediscurso, que passam a se manifestar, na superfície do texto, por meio de um conglomerado de formas referenciadoras, as quais são passíveis de inferências, e cujo funcionamento conduz ao estabelecimento de um elemento que se constitui como essencial para construção da atividade interacional.

Em vista da análise realizada, proponho que as estratégias de cataforização atuam como instrumentos introdutórios do processo de construção de referentes a serem postos na cadeia textual, que, em se tratando das histórias sob análise, constituem recursos importantes para estruturação do processo narrativo, já que atuam como espécies de elementos plóticos ou de suspense no processo de desvelamento de um dado referente, mais precisamente, aqui, no que diz respeito aos elementos afiliados ao lendário inseridos nos textos estudados.

A tabela 1, a seguir, apresenta as ocorrências de Elementos Catafóricos ligados a referentes temáticos:

\section{Tabela 1 - Estratégias catafóricas que apontam para referentes temáticos a serem postos na cadeia textual}

\begin{tabular}{l|rrrrr}
\hline Narrativas referentes aos personagens lendários & Boto & Cobra Matintaperera & Curupira & Total \\
\hline Número de Narrativas & 4 & 5 & 5 & 3 & 17 \\
Ocorrências de elementos catafóricos & 78 & 68 & 60 & 30 & 236 \\
Percentual (\%) & 33,06 & 28,81 & 25,42 & 12,71 & 100 \\
\hline
\end{tabular}

Fonte: Revista Visagens, Assombrações e Encantamentos da Amazônia.

Os dados expressos na tabela apresentam uma totalidade de 236 ocorrências de formas catafóricas, que resulta numa média de 13,88 dessas formas por narrativa. Em termos de percentual, a maior ocorrência se deu nas narrativas de Boto, com 33,06\%, figurando, em seguida, as de Cobra, com 28,81\%. Em terceiro lugar as de Matinta, que somam $25,42 \%$ e, por fim, as de Curupira, que alcançaram $12,71 \%$.

Desse modo, o somatório de ocorrências de Elementos Catafóricos associados a referentes temáticos mostrou-se bastante elevado, mais diretamente no que diz respeito aos processos de constituição de recursos referenciais nas histórias em investigação.

\footnotetext{
${ }^{4} \mathrm{O}$ sentido proposto pelas expressões pré-figurar e pré-construir indicam, nesse âmbito, que um dado referente temático pode ser antecipado inicialmente por determinadas expressões, as quais têm a função de colocar em ação o processo de construção prévia desse referente dentro da cadeia referencial.
} 
As narrativas de Boto tiveram um percentual maior de estratégias catafóricas, com $33,06 \%$ em total de narrativas analisadas, trazendo evidências de que essas narrativas estão propensas à realização desse tipo de estratégia. É possível também que esse fenômeno se dê em razão de fatores sociocognitivos e sociodiscursivos ${ }^{5}$, compreendendo $^{-}$ ainda, nesse caso, o fato de o autor dessas narrativas ter se apropriado das estratégias em questão por meio do contato com determinados gêneros textuais, nos quais elas são utilizadas com certa frequência. Quanto à média por narrativa, considerando as 17 (dezessete) estudadas, temos 13,88 de ocorrências, o que constitui um resultado importante no que concerne à incidência dessa expressão referencial.

Conforme os dados apresentaram, as narrativas de Boto foram as que tiveram o maior índice percentual de estratégias catafóricas, o que pode se dar em razão de que contêm, em sua construção sociodiscursiva, poucas formas de metamorfose e, em vista disso, apresentam certa estabilidade no que diz respeito a essa mesma construção, daí o autor utilizar-se de maneira intensa de recursos catafóricos ou antecipatórios, os quais passam a funcionar como instrumentos discursivos por meio dos quais o(a) Boto(a) é apresentado(a) como um personagem novo/inusitado na atividade narrativa, e não como um personagem já conhecido ou comum. Por outro lado, por se tratar de um personagem bastante estabilizado e reificado, o escritor cria estratégias inovadoras no seu processo de caracterização/construção, criando formas prévias de suspense do referente a ser posto na cadeia textual, de um referente que, não sendo novo, passa também a se instituir como novo, pelo menos se consideramos o modo como ele reconstrói/reconstitui o personagem em questão no curso da progressão referencial e da atividade tópica.

Pelo lado oposto, no caso da Cobra, que também teve percentual bastante alto de estratégias catafóricas, é possível afirmar que estas ocorram mesmo em razão das diversas formas de metamorfose de que essa entidade é detentora, daí serem os processos catafóricos resultado dos vários modos de transformação por que passa esse personagem no contexto cultural de histórias deste tipo. Já no que se refere ao Curupira, o percentual de catáforas foi o mais baixo, o que pode estar ligado ao fato de que tal personagem também não possui alternativas de metamorfose, apresentando-se como mais ou menos estável no universo sociocultural de sua construção e circulação, especificamente no que concerne às formas de constituição de histórias relativas a esse personagem do lendário.

Enfim, é possível postular que as estratégias em estudo demarquem ou indiciem processos sociocognitivos e culturais envolvidos na construção das histórias sob análise, referendando que os elementos catafóricos integram estratégias textuais típicas do contexto de produção desses relatos, as quais o produtor textual convoca, já que, de maneira direta ou indireta, está imerso no contexto em que são produzidas essas histórias.

\footnotetext{
5 Os fatores sociocognitivos e sociodiscursivos, aqui postulados, encampam diferentes processos de apropriação de significados em circulação no contexto de produção das narrativas sob análise. Os fatores sociocognitivos dizem respeito à circulação de sentidos por meio dos quais as narrativas em estudo são construídas, o que leva o produtor textual a reconstruí-los quando do processo de constituição das narrativas em análise. Os fatores sociodiscursivos referem-se, aqui, à apropriação de elementos discursivos ligados aos contextos em que as narrativas em estudo circulam.
}

MOURA, Heliud Luis Maia. Estratégias catafóricas em narrativas amazônicas: implicações para a construção da cadeia tópica e textual. Linguagem em (Dis)curso - LemD, Tubarão, SC, v. 18, n. 2, p. 273-286, maio/ago. 2018. 
APOTHÉLOZ, D.; REICHLER-BÉGUELIN, M.-J. Construction de la référence et stratégies de désignation. In: BERRENDONNER, A.; REICHLER-BÉGUELIN, M.-J. (Eds.). TRANEL n. 23. Du syntagme nominal aux objets-de-discours. Neuchâtel: Université de Neuchâtel, déc. 1995. p. 227-271.

KOCH, I. G. V. Referenciação: construção discursiva. Ensaio apresentado por ocasião do concurso para titular em Análise do Discurso do IEL/Unicamp, dez. 1999.

Desvendando os segredos do texto. São Paulo: Cortez, 2002.

Introdução à lingüística textual: trajetória e grandes temas. São Paulo: Martins Fontes, 2004.

MARCUSCHI, L. A. Cognição, linguagem e práticas interacionais. Rio de Janeiro: Lucerna, 2007.

MONTEIRO, W. Encontro com o curupira. In: Visagens e assombrações e encantamentos da Amazônia. 3. ed., n. 2, Ano I. Belém: Smith - Produções Gráficas, 2000a. p. 21.

Uma namorada e dois irmãos. In: Visagens e assombrações e encantamentos da Amazônia. 2. ed., n. 5, Ano II. Belém: Smith - Produções Gráficas, 2000b. p. 15-17.

A cobra grande de Barreira do Tapará. In: Visagens e assombrações e encantamentos da Amazônia. 2. ed., n. 7, Ano III. Belém: Smith - Produções Gráficas. 2002. p.15-16.

A tia Podó. In: Visagens e assombrações e encantamentos da Amazônia. 2. ed. n. 8, Ano IV. Belém: Smith - Produções Gráficas. 2007. p. 15-18.

MOURA, H. L. M. Atividades de referenciação em narrativas afiliadas ao universo do lendário da Amazônia: implicações sociocognitivas e culturais. 2013. 338 f. Tese (Doutorado em Linguística) Instituto de Estudos da Linguagem, Universidade Estadual de Campinas, Campinas, 2013.

TOMASELLO, M. Origens culturais da aquisição do conhecimento humano. São Paulo: Martins Fontes, 2003.

Recebido em: 25/05/17. Aprovado em: 30/12/17.

Title: Cataphoric strategies in Amazonian narratives: implications for the construction of the topical and textual chain

\section{Author: Heliud Luis Maia Moura}

Abstract: This article aims to analyze cataphoretic strategies mobilized in narratives affiliated to the universe of the legendary Amazon, observing, according to the theories about the reference, the way in which these strategies anticipate and project referring to being put in the textual chain. It takes, as theoretical reference, postulations by Tomasello (2003), Marcuschi (2007), Koch (1999, 2002, 2004) and Moura (2013). According to the theoretical postulates, it considers the reference a discursive, sociocognitive and sociointeractive activity, by which we reconstruct in language, beings, objects and events of the biossocial universe. Thereunto, reality is constructed by the way we act sociocognitively about this universe (KOCH, 2004). The corpus in analysis consists of 5 (five) excerpts from narratives of Boto, Cobra, Matintaperera and Curupira. The analysis reaffirms the premise the cataphoric strategies are tributary to sociocognitive and cultural processes in circulation in the context in which the narratives previously mentioned circulate and are produced.

Keywords: Textual Linguistics. Reference. Amazonian Narrative. Cataphoric strategy.

Título: Estrategias catafóricas en narrativas amazónicas: implicaciones para construcción de la cadena tópica y textual

Autor: Heliud Luis Maia Moura

Resumen: Este artículo objetiva analizar estrategias catafóricas movilizadas en narrativas afiliadas al universo del legendario de la Amazonia, observando, de acuerdo con las teorías acerca de la referencia, la forma como esas estrategias anticipan y proyectan referentes a ser puestos en la cadena textual. El referencial teórico es compuesto de postulaciones de Tomasello (2003), Marcuschi (2007), Koch (1999, 2002, 2004) y Moura (2013). Conforme a las postulaciones teóricas, considera la referencia una actividad discursiva, sociocognitiva y socio-interactiva, por la cual reconstruimos, en lenguaje, seres, objetos y eventos

MOURA, Heliud Luis Maia. Estratégias catafóricas em narrativas amazônicas: implicações para a construção da cadeia tópica e textual. Linguagem em (Dis)curso - LemD, Tubarão, SC, v. 18, n. 2, p. 273-286, maio/ago. 2018. 
del universo bio-social. Así, la realidad es construida por la manera en que actuamos sociocognitivamente sobre ese universo (KOCH, 2004). El corpus en análisis es compuesto por 5 (cinco) extractos de narrativas de Boto, Cobra, Matintaperera y Curupira. El análisis hecho reafirma la premisa de que las estrategias catafóricas son tributarias de procesos sociocognitivos y culturales en circulación en el contexto en que las narrativas mencionadas circulan y son producidas.

Palabras clave: Lingüística textual. Referenciación. Narrativa amazónica. Estrategia catafórica.

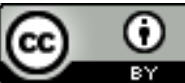

Este texto está licenciado com uma Licença Creative Commons Atribuição 4.0 Internacional. 